\title{
ESTOQUE E FRAÇÕES DA MATÉRIA ORGÂNICA DE LATOSSOLO CULTIVADO COM CAFEEIRO EM DIFERENTES ESPAÇAMENTOS DE PLANTIO ${ }^{(1)}$
}

\author{
Otacílio José Passos Rangel ${ }^{(2)}$, Carlos Alberto Silva ${ }^{(3)}$ \& Paulo \\ Tácito Gontijo Guimarães ${ }^{(4)}$
}

\begin{abstract}
RESUMO
Este estudo teve como objetivo avaliar o efeito de espaçamentos de plantio do cafeeiro sobre os estoques de carbono e nitrogênio e sobre os teores e distribuição de C em frações da matéria orgânica de um Latossolo Vermelho distroférrico típico. Foi avaliado um experimento conduzido durante 11 anos na Fazenda Experimental da EPAMIG, em Machado (MG), cujos tratamentos consistiram da combinação de quatro espaçamentos entre linhas $(2,0,2,5,3,0$ e 3,5 m) com três espaçamentos entre plantas $(0,5,0,75$ e $1,0 \mathrm{~m})$ de cafeeiro. Uma área sob mata nativa próxima ao experimento foi utilizada como referência. Para avaliação dos estoques de $C$ orgânico (CO) e N total (NT) e realização do fracionamento físico-densimétrico da matéria orgânica, as amostras de solo foram coletadas na entrelinha (EL) e na projeção da copa (PC) do cafeeiro. Os estoques de CO e os teores de C-FL na entrelinha do cafeeiro são iguais ou superiores àqueles determinados para as amostras da projeç̃o da copa. Os estoques totais de CO e de NT e as outras frações da matéria orgânica do solo avaliadas não são influenciados pelo espaçamento entre plantas e entre linhas, pela área de planta e pela população de cafeeiro.
\end{abstract}

Termos de indexação: Coffea arabica L., densidade de plantio, estoque de carbono, nitrogênio, frações orgânicas, frações granulométricas.

\footnotetext{
(1) Parte da Tese de Doutorado do primeiro autor desenvolvida no Departamento de Ciência do Solo da Universidade Federal de Lavras - UFLA. Recebido para publicação em maio de 2006 e aprovado em junho de 2007.

${ }^{(2)}$ Doutor em Agronomia, Universidade Federal de Lavras - UFLA. Caixa Postal 3037, CEP 37200-000 Lavras (MG). E-mail: otaciliorangel@yahoo.com.br.

(3) Professor Adjunto do Departamento de Ciência do Solo, UFLA. E-mail: csilva@ufla.br.

(4) Pesquisador da Empresa de Pesquisa Agropecuária de Minas Gerais/CTSM. Caixa Postal 176, CEP 37200-000 Lavras (MG). E-mail: paulotgg@ufla.br
} 


\title{
SUMMARY: STORAGEAND FRACTIONS OFORGANICMATTER OF ANOXISOL UNDER COFFEE PLANTATIONS WITH DIFFERENT PLANT SPACINGS
}

\begin{abstract}
This study aimed to evaluate the effect of coffee planting spacing on soil carbon and nitrogen storage and on the contents and distribution of organic matter fractions (light and heavy) of a dystroferric Red Latosol (Oxisol). An experiment installed 11 years ago on an experimental farm of EPAMIG in Machado (Minas Gerais State, Brazil) was evaluated. The treatments consisted of the combination of four spacings between rows $(2.0,2.5,3.0$ and $3.5 \mathrm{~m})$ with three spacings between plants $(0.5,0.75$ and $1.0 \mathrm{~m})$. As reference, soil samples were also colleted in a native forest area adjacent to the experiment. For the evaluation of organic carbon $(O C)$, total nitrogen $(T N)$ storage and density fractions of organic matter, soil samples were collected in-between rows (IR) and in the coffee canopy projection (CP). Organic $C$ stocks and $C$-light fraction contents measured in-between coffee rows are equal to or higher than those verified in the coffee canopy projection. The coffee plant area and stand, and the distance between coffee trees and planting rows had no influence on the soil OC and TN stocks or the other analyzed fractions of soil organic matter.
\end{abstract}

Index terms: Coffea arabica L., planting density, carbon storage, nitrogen, organic fractions, granulometric fractions.

\section{INTRODUÇÃO}

A escolha do espaçamento para o plantio da lavoura cafeeira se constitui em tema muito debatido, sendo grande o número de demandas de pesquisa quanto às vantagens e desvantagens de utilizar mais ou menos plantas por unidade de área. Tradicionalmente, a maioria das lavouras cafeeiras foi implantada em espaçamentos mais largos (1.000 a 2.000 plantas por hectare); contudo, a partir da década de 1980, tornouse comum o cultivo de cafeeiro adensado, em que os estandes são constituídos por maior número de plantas por hectare (5.000 a 10.000 plantas). A partir dos anos 90, as lavouras cafeeiras em sistema adensado apresentaram grande expansão, embora, no plano nacional, não ocupem ainda espaço significativo. Estima-se, atualmente, que o sistema tradicional e o em renque ocupem, respectivamente, 50 e $28 \%$ da área cafeeira do Brasil, enquanto os sistemas adensado e semi-adensado representam, apenas, 10 e $12 \%$, respectivamente, da área plantada (Thomasiello, 2001).

O declínio contínuo da capacidade produtiva do solo tem sido um dos maiores problemas associados aos plantios de cafeeiro em espaçamentos largos ou com baixa densidade de plantas. Sob essas condições, a erosão, a lixiviação e a oxidação da matéria orgânica contribuem para acidificação e perda da fertilidade do solo. Por outro lado, o adensamento da lavoura cafeeira é um sistema conservacionista que protege $o$ solo, diminuindo o processo erosivo e a perda de nutrientes por lixiviação e de matéria orgânica por oxidação, proporciona melhor manejo dos resíduos vegetais e aumenta a ciclagem de nutrientes, sobretudo do N (Pavan \& Chaves, 1996).
A matéria orgânica do solo (MOS) é um importante atributo a ser considerado na avaliação de sistemas de uso e manejo do solo (Doran \& Parkin, 1994). Em regiões de clima tropical e subtropical úmido, o rápido declínio na MOS ocorre principalmente em sistemas de manejo convencionais, que envolvem intensa perturbação do solo (Tiessen et al., 1992; Parfitt et al., 1997). O estoque de C orgânico (CO) é determinado pela diferença entre as quantidades de $\mathrm{C}$ que são adicionadas (aporte de resíduos vegetais) e perdidas do solo em função da decomposição da matéria orgânica, erosão e lixiviação (Dalal \& Mayer, 1986). De acordo com Pavan \& Chaves (1996), o incremento na densidade de plantio em lavouras cafeeiras aumenta os estoques de $\mathrm{CO}$ do solo, em razão do maior aporte de resíduos vegetais oriundos de folhas e ramos do cafeeiro depositados naturalmente ou desprendidos durante a colheita e dos compostos orgânicos liberados pelas raízes (exsudatos, mucilagens e células mortas). Considerando a possibilidade de aumento do estoque de $\mathrm{CO}$ pelo plantio de lavouras cafeeiras no sistema adensado, deve-se ressaltar que esse aumento também depende de outros fatores, como clima (principalmente temperatura e precipitação), textura e mineralogia do solo (Alvarez \& Lavado, 1998). Segundo Pavan \& Chaves (1996), o acúmulo de matéria orgânica no solo em áreas de cultivo de cafeeiro é de suma importância, tendo em vista que a matéria orgânica pode contribuir com mais de 90 \% da capacidade de troca de cátions do solo.

O estudo da matéria orgânica e de seus diversos compartimentos, bem como sua relação com o manejo, visa desenvolver estratégias para utilização sustentável dos solos, com vistas a reduzir o impacto 
das atividades agrícolas sobre o meio ambiente (Pinheiro et al., 2004). Estudos da MOS por meio da extração e fracionamento das substâncias húmicas têm sido realizados para o entendimento da pedogênese, das interações organominerais, da melhoria de características físicas do solo, da diminuição da fixação de fósforo e do impacto da agricultura na qualidade do solo (Benites et al., 1999; Longo \& Espíndola, 2000; Roscoe \& Machado, 2002). Entretanto, os métodos de fracionamento químico pouco têm contribuído para identificação de compartimentos da MOS que são alterados sob manejo intensivo e, de modo distinto, ao longo do tempo (Cambardella \& Elliott, 1992; Christensen, 1992). O fracionamento físicodensimétrico da MOS tem se mostrado promissor na distinção de compartimentos de $\mathrm{C}$ do solo sujeitos à influência dos sistemas de manejo e na identificação de mecanismos que conferem proteção física à matéria orgânica (Collins et al., 1997), além de caracterizar as relações entre a matéria orgânica e a agregação do solo (Feller et al., 1997; Freixo et al., 2002b).

O fracionamento físico-densimétrico separa a MOS em dois compartimentos principais, baseando-se nas densidades específicas das frações orgânicas, a saber: (a) fração leve (FL), com densidade menor que $1,7 \mathrm{~kg} \mathrm{dm}^{-3}$, que consiste de um compartimento com grau de decomposição intermediário entre os resíduos vegetais e a matéria orgânica estabilizada e humificada, apresentando relação C:N maior que a do solo e representando, na maioria das vezes, a menor fração do compartimento morto da MOS, que engloba, comumente, de 10 a $30 \%$ do CO do solo; e (b) fração pesada (FP), composta de materiais orgânicos adsorvidos ou depositados pelos microrganismos na superfície dos agregados, podendo conter mais de $90 \%$ do CO do solo (Barrios et al., 1996). A FL, por ser menos densa, é separada da FP por flotação, por meio do uso de soluções orgânicas ou inorgânicas com alta densidade (Christensen, 1992). A FL é considerada o compartimento biologicamente ativo ou lábil da MOS (Janzen et al., 1992; Barrios et al., 1996).

A dinâmica das frações da matéria orgânica está intimamente relacionada com a textura do solo (Feller \& Beare, 1997). Assim, solos arenosos apresentam maior proporção do $\mathrm{CO}$ associado às partículas de areia $(>53 \mu \mathrm{m}$ ), o que lhes confere maior fragilidade quanto às mudanças nos sistemas de manejo do solo, uma vez que esta fração, composta principalmente de resíduos vegetais, é facilmente mineralizada (Freixo et al., 2002b). Em solos argilosos, as frações orgânicas encontram-se mais associadas à argila e ao silte, de forma que as quantidades de $\mathrm{C}$ associadas à areia não perfazem mais do que $10 \%$ do total de $\mathrm{CO}$ do solo (Rosell et al., 1996).

Nas lavouras cafeeiras, é comum o acúmulo de resíduos vegetais nas entrelinhas de plantio, em razão da prática de arruação. Ao término da colheita, somente parte dos resíduos é retornada à projeção da copa. Em função da retirada, do menor aporte de resíduos e da maior perda de $\mathrm{CO}$ por oxidação na projeção da copa, ao longo do tempo, pode ocorrer maior armazenamento de CO e de C-FL na entrelinha. É bastante provável que a diminuição do espaçamento entre linhas de cafeeiro, em função da maior eficiência na ciclagem de $\mathrm{C}$ e de outros nutrientes, da menor decomposição da MOS e do maior aporte de resíduos, propicie as condições necessárias para aumento dos estoques totais de $\mathrm{C} \mathrm{e} \mathrm{N}$ e dos teores de $\mathrm{C}$ associado à fração leve. Os resultados obtidos em estudos dessa natureza podem auxiliar na escolha de espaçamentos de plantio de cafeeiro que propiciem maior acúmulo e melhoria na qualidade da matéria orgânica do solo.

Assim, este estudo teve por objetivo avaliar os efeitos de diferentes espaçamentos de plantio do cafeeiro sobre os estoques de $\mathrm{C}$ e $\mathrm{N}$ e sobre os teores e a distribuição de $\mathrm{C}$ associado a diferentes frações da matéria orgânica de Latossolo Vermelho distroférrico.

\section{MATERIAL E MÉTODOS}

O estudo foi realizado na Fazenda Experimental da Empresa de Pesquisa Agropecuária de Minas Gerais (EPAMIG), localizada a $10 \mathrm{~km}$ do município de Machado (MG). O solo da área experimental foi classificado como Latossolo Vermelho distroférrico típico, textura média, de acordo com Embrapa (1999). No início do experimento, o solo apresentava, na camada de $0-20 \mathrm{~cm}, \mathrm{pH}$ em água $=4,0 ; \mathrm{Ca}^{2+}=0,2 \mathrm{cmol}_{\mathrm{c}} \mathrm{kg}^{-1}$; $\mathrm{Mg}^{2+}=0,1 \mathrm{cmol}_{\mathrm{c}} \mathrm{kg}^{-1} ; \mathrm{P}$ (Mehlich-1) = 1,0 mg kg-1; $\mathrm{K}^{+}=11 \mathrm{mg} \mathrm{kg}^{-1} ; \mathrm{e} \mathrm{Al}^{3+}=0,5 \mathrm{cmol}_{\mathrm{c}} \mathrm{kg}^{-1}$. Os teores de argila, silte e areia eram, respectivamente, de 270 , 290 e $440 \mathrm{~g} \mathrm{~kg}^{-1}$. O método utilizado na avaliação dos atributos químicos do solo está descrito em Embrapa (1979). A análise granulométrica foi realizada de acordo com o método da pipeta (Day, 1965), após dispersão com $\mathrm{NaOH} 1 \mathrm{~mol} \mathrm{~L}^{-1}$ e agitação rápida (6.000 rpm) da amostra por $15 \mathrm{~min}$.

Antes da implantação do experimento a campo, foi realizada, em novembro de 1991, a calagem do solo da área experimental, com o objetivo de elevar a saturação por bases a $60 \%$. O calcário dolomítico foi aplicado em área total e incorporado na camada de solo de $0-20 \mathrm{~cm}$. A instalação do experimento a campo, caracterizada pelo plantio das mudas do cafeeiro, foi realizada em janeiro de 1992, sulcando-se o solo de acordo com os espaçamentos a serem estudados, utilizando no plantio o cultivar Catuaí Vermelho IAC-44, com uma planta por cova. Durante a realização do experimento (1992 a 2003), o cafeeiro foi mantido livre de plantas invasoras por meio de capinas manuais (cinco a seis capinas por ano) e aplicações de herbicidas. Os resíduos vegetais foram depositados nas entrelinhas de plantio, de forma a manter o solo sob a projeção da copa descoberto durante a maior parte do ano. A partir de 1994, no mês que antecedia a colheita, foi realizada a arruação, prática que consiste em concentrar os resíduos vegetais e parte da camada superior do solo da projeção 
da copa nas entrelinhas de plantio. É comum que, ao término da colheita, somente uma parte do material depositado nas ruas de cafeeiro retorne para a projeção da copa. Após 10 anos de condução do experimento (julho de 2002), procedeu-se à recepa das plantas a $40 \mathrm{~cm}$ de altura do solo. Quatro meses após a recepa, foi feita a desbrota, deixando-se duas hastes por tronco, no sentido da linha de plantio. Todos os resíduos vegetais oriundos dessas práticas foram triturados e depositados nas entrelinhas de plantio. A correção da acidez do solo, quando necessária, e as adubações para implantação, formação, produção e formação pósrecepa do cafeeiro foram efetuadas com base na análise química do solo, seguindo-se as recomendações descritas em CFSEMG (1989).

Os tratamentos avaliados consistiram da combinação de quatro espaçamentos entre linhas $(2,0$; 2,$5 ; 3,0$ e 3,5 m) com três espaçamentos entre plantas $(0,5,0,75$ e $1,0 \mathrm{~m})$, totalizando 12 tratamentos, dispostos no campo em blocos ao acaso, em esquema fatorial $4 \times 3$, com três repetições. As parcelas experimentais mediam $12 \mathrm{~m}$ de comprimento e possuíam três linhas de plantio, cujas distâncias entre si variaram em função do tratamento estudado. A parcela útil considerada na etapa de coleta das amostras de solo foi a linha central (interna), uma vez que esta sofreu a influência tanto do adensamento entre linhas como entre plantas na linha. A densidade populacional variou, em função dos tratamentos, de 2.857 a 10.000 plantas ha ${ }^{-1}$.

A amostragem do solo foi realizada em dezembro de 2003, 11 anos após o estabelecimento do experimento a campo. As amostras foram coletadas em dois pontos de cada parcela experimental, na projeção da copa (PC) e na entrelinha de cultivo (EL), onde eram depositados, antes das colheitas, os resíduos culturais (podas e recepas) e os provenientes das capinas da PC. Foram coletadas ao acaso cinco amostras simples em cada ponto (EL e PC), que foram misturadas para formar uma amostra composta por parcela. As amostras foram coletadas nas profundidades de solo de 0-10, 10-20 e 20-40 cm, para avaliação dos teores e cálculo dos estoques de C orgânico (CO) e $\mathrm{N}$ total (NT), e nas profundidades de $0-5$ e 0-10 cm, para determinação dos teores de $\mathrm{C}$ associado às frações leve e pesada da matéria orgânica. Para avaliação da densidade do solo, coletaram-se três amostras indeformadas em cada espaçamento, ponto de coleta e profundidade $(0-10,10-20$ e $20-40 \mathrm{~cm})$, com auxílio de um anel volumétrico de $100 \mathrm{~cm}^{3}$. Numa área de mata nativa, a cerca de um quilômetro do experimento, com a mesma classe de solo e sem histórico de intervenção humana, foram coletadas, nas mesmas profundidades de coleta da área experimental, amostras que foram utilizadas como referência.

As amostras compostas foram acondicionadas em sacos plásticos e conduzidas ao laboratório. Para análise dos teores de CO e NT, necessários ao cálculo dos estoques desses elementos em solo, as amostras foram secas ao ar, destorroadas, trituradas em almofariz e passadas em peneira de malha de $0,210 \mathrm{~mm}$. As amostras utilizadas na etapa de fracionamento físico-densimétrico da MOS foram secas ao ar, destorroadas e passadas em peneira de $2 \mathrm{~mm}$ (terra fina seca ao ar-TFSA).

O C orgânico (CO) foi determinado pelo método descrito em Yeomans \& Bremner (1988), após digestão de $0,3 \mathrm{~g}$ de solo com $5 \mathrm{~mL}$ de $\mathrm{K}_{2} \mathrm{Cr}_{2} \mathrm{O}_{7} 0,167 \mathrm{~mol} \mathrm{~L}^{-1} \mathrm{e}$ $10 \mathrm{~mL}$ de $\mathrm{H}_{2} \mathrm{SO}_{4}$ p.a., por $30 \mathrm{~min}$ a $170{ }^{\circ} \mathrm{C}$, em bloco digestor de 40 provas. Após resfriamento em temperatura ambiente, os extratos foram transferidos quantitativamente para frascos erlenmeyers de $125 \mathrm{~mL}$, utilizando-se água destilada para obter volume final de aproximadamente $75 \mathrm{~mL}$. Em seguida, a cada erlenmeyer, foram adicionados $5 \mathrm{~mL}$ de $\mathrm{H}_{3} \mathrm{PO}_{4}$ p.a., procedendo-se à titulação com solução de $\mathrm{Fe}\left(\mathrm{NH}_{4}\right)_{2}\left(\mathrm{SO}_{4}\right)_{2} \cdot 6 \mathrm{H}_{2} \mathrm{O} 0,4 \mathrm{~mol} \mathrm{~L}^{-1}$ (sal de Mohr), utilizando-se como indicador a solução ácida de difenilamina - $10 \mathrm{~g} \mathrm{~L}^{-1}$. Paralelamente, foram realizadas provas em branco, com e sem aquecimento.

$\mathrm{O} \mathrm{N}$ total (NT) foi determinado seguindo-se o método descrito em Bremner (1996), que preconiza o uso de uma mistura digestora à base de $\mathrm{K}_{2} \mathrm{SO}_{4}, \mathrm{CuSO}_{4}$ e Se. A cada amostra de $0,1 \mathrm{~g}$ de solo foi adicionado $1,1 \mathrm{~g}$ da mistura digestora e $3,0 \mathrm{~mL}$ de $\mathrm{H}_{2} \mathrm{SO}_{4}$ p.a. A digestão foi feita a $350^{\circ} \mathrm{C}$, com posterior destilação a vapor. $\mathrm{O}$ destilado foi recolhido em uma solução de $\mathrm{H}_{3} \mathrm{BO}_{3}\left(20 \mathrm{~g} \mathrm{~L}^{-1}\right)$, misturada a uma solução de verde de bromocresol e vermelho de metila, e titulado com solução de $\mathrm{HCl} 0,01 \mathrm{~mol} \mathrm{~L}^{-1}$. Os estoques de $\mathrm{CO}$ e NT, em cada profundidade do solo, foram calculados pelo uso da seguinte fórmula: estoque de $\mathrm{CO}$ ou NT $\left(\mathrm{t} \mathrm{ha}{ }^{-1}\right)=$ teor de $\mathrm{C}$ ou $\mathrm{N}\left(\mathrm{g} \mathrm{kg}^{-1}\right) \times \mathrm{Ds} \times \mathrm{e} / 10$, em que $\mathrm{Ds}=$ densidade do solo na profundidade $\left(\mathrm{kg} \mathrm{dm}^{-3}\right) \mathrm{e} \mathrm{e}$ = espessura da camada de solo $(\mathrm{cm})$. Para avaliar os estoques totais de C e NT, foi calculada a média ponderada a partir dos estoques obtidos na EL e na PC do cafeeiro, considerando uma faixa de solo sob influência da PC, para todos os tratamentos, de 1,2 m. Dessa forma, as faixas de solo consideradas sob influência da EL foram de 0,8, 1,3, 1,8 e 2,3 m, respectivamente, para os espaçamentos entre linhas de 2,0, 2,5, 3,0 e 3,5 m.

As frações leve e pesada da matéria orgânica foram obtidas seguindo-se as marchas analíticas descritas em Sohi et al. (2001) e Machado (2002). O procedimento analítico para separação da fração leve (FL) foi realizado em triplicata, para cada amostra de solo. Em frascos de centrífuga de $50 \mathrm{~mL}$, foram adicionados $5 \mathrm{~g}$ de TFSA e $35 \mathrm{~mL}$ da solução de iodeto de sódio (NaI), com densidade de $1,8 \pm 0,1 \mathrm{~g} \mathrm{~cm}^{-3}$. Os frascos com a mistura foram agitados manualmente por 30 seg, visando dispersar os agregados instáveis e permitir a flotação da fração leve (FL) na solução de $\mathrm{NaI}$, sendo, a seguir, centrifugados a $8.000 \mathrm{~g}$, por 30 min. Após centrifugação, a FL presente na superfície da solução de $\mathrm{NaI}$ foi aspirada e filtrada em sistema com vácuo (Sistema Asséptico Sterifil, $47 \mathrm{~mm}$-Millipore), 
utilizando-se nesta etapa filtro de fibra de vidro de $47 \mathrm{~mm}$ de diâmetro e de $2 \mu \mathrm{m}$ de poro de retenção. A FL retida nos filtros foi cuidadosamente lavada com água destilada, visando remover o excesso de $\mathrm{NaI}$, sendo, a seguir, levada à estufa de circulação forçada de ar para secar a $65^{\circ} \mathrm{C}$, durante $72 \mathrm{~h}$. Para determinação do teor de $\mathrm{C}$ na fração leve $\left(\mathrm{C}_{\mathrm{FL}}\right)$, foram pesados o filtro mais o resíduo orgânico separado. A seguir, a fração leve foi macerada em almofariz e passada em peneira de malha de $0,210 \mathrm{~mm}$.

$\mathrm{Na}$ determinação dos teores de $\mathrm{C}$ associado às frações granulométricas do solo (fração pesada-FP), três repetições foram transferidas para frasco de $350 \mathrm{~mL}$ (Nalgene), utilizando-se água destilada para obter volume final de $250 \mathrm{~mL}$. A separação da fração pesada foi realizada seguindo-se o método descrito em Gavinelli et al. (1995). A cada frasco de $350 \mathrm{~mL}$ foi adicionado $0,5 \mathrm{~g}$ de hexametafosfato de sódio $\left(\mathrm{NaPO}_{3}\right)_{\mathrm{n}}$, sendo a mistura agitada por aproximadamente $14 \mathrm{~h}$, a $250 \mathrm{rpm}$. A separação da fração areia $(>53 \mu \mathrm{m})$ do silte e argila foi realizada por peneiramento úmido. As frações silte $(2-53 \mu \mathrm{m})$ e argila $(0-2 \mu \mathrm{m})$ foram separadas a partir da coleta de alíquotas das frações granulométricas de $0-53 \mu \mathrm{m}$ (argila + silte) e $0-2 \mu \mathrm{m}$ (argila), em função dos tempos de sedimentação dessas partículas. A seguir, as frações foram secas em estufa de circulação forçada de ar a $65^{\circ} \mathrm{C}$, pesadas, maceradas em almofariz e peneiradas (malha de $0,210 \mathrm{~mm}$ ), para posterior determinação deste teor. A determinação do teor de $\mathrm{C}$ nas frações leve e pesada (C-areia, C-argila + silte e C-argila) foi realizada seguindo-se a metodologia descrita em Yeomans \& Bremner (1988). O teor de C na fração silte (C-silte) foi obtido indiretamente, em razão da diferença dos teores de $\mathrm{C}$ nas frações argila + silte e argila.

Os dados relativos aos estoques de $\mathrm{CO}$ e NT e de $\mathrm{C}$ em frações da matéria orgânica foram submetidos à análise de variância, para verificação, em cada profundidade de solo, dos efeitos dos espaçamentos de plantio e dos pontos de coleta das amostras de solo (EL e PC) sobre os atributos analisados. Os dados levantados na área de mata foram excluídos da análise estatística, pelo fato de o local não compor o desenho experimental. As médias foram comparadas pelo teste de Scott-Knott a $5 \%$, utilizando-se o aplicativo computacional Sisvar (Ferreira, 2000).

\section{RESULTADOS E DISCUSSÃO}

\section{Estoques de carbono e nitrogênio}

As médias dos estoques de CO e NT, para o solo de mata e para os diferentes espaçamentos de plantio do cafeeiro e pontos de coleta das amostras de solo, são mostradas no quadro 1. Observa-se que, exceto na camada de solo de 10-20 cm, houve efeito significativo dos espaçamentos de plantio e pontos de coleta das amostras de solo sobre os estoques de CO e NT. As maiores diferenças nos estoques de $\mathrm{CO}$, em função dos espaçamentos de plantio, foram observadas na camada superficial do solo $(0-10 \mathrm{~cm})$.

Em relação ao solo de mata, o cultivo do cafeeiro por 11 anos resultou em redução nos estoques de $\mathrm{CO}$ e NT nas amostras coletadas na projeção da copa, em todos os espaçamentos avaliados. Na camada de solo de $0-10 \mathrm{~cm}$, em relação à mata, foram verificadas reduções médias de 45 e $30 \%$, nos estoques de $\mathrm{CO}$ e NT, respectivamente. Para as amostras coletadas na entrelinha, os estoques de CO e NT foram maiores do que na mata, principalmente nos maiores espaçamentos entre linhas de plantio. Na camada superficial de solo, os estoques de CO da entrelinha foram iguais ou superiores àqueles verificados na projeção da copa de cafeeiro. É comum, em áreas cultivadas, haver redução acentuada no conteúdo de matéria orgânica do solo (Bonde et al., 1992; Silva et al., 1999), como ocorreu na projeção da copa do cafeeiro. A maior preservação ou os aumentos de estoque de CO notados na EL podem ser explicados pelo grande aporte de resíduos vegetais nesse local, em conseqüência da deposição de restos de capinas, restos culturais, resíduos da recepa, etc.

Os estoques de $\mathrm{CO}$ de todos os espaçamentos de plantio do cafeeiro variaram, na EL, entre 21,3 e $31,7 \mathrm{t} \mathrm{ha}^{-1}$, na profundidade de $0-10 \mathrm{~cm}$, de 20,9 a $30,4 \mathrm{t} \mathrm{ha}^{-1}$, na profundidade de $10-20 \mathrm{~cm}$, e de $35,4 \mathrm{a}$ $47,8 \mathrm{t} \mathrm{ha}^{-1}$, na profundidade de $20-40 \mathrm{~cm}$. Na PC, as variações foram de 17,2 a $24,8 \mathrm{t} \mathrm{ha}^{-1}$, na profundidade de $0-10 \mathrm{~cm}$, de 16,3 a $29,8 \mathrm{t} \mathrm{ha}^{-1}$, na profundidade de 10-20 cm, e de 34,7 a 44,0 $\mathrm{t} \mathrm{ha}^{-1}$, na profundidade de 20-40 cm (Quadro 1). A média do estoque de CO do solo acumulado na camada de $0-40 \mathrm{~cm}$ na PC $\left(83,5 \mathrm{t} \mathrm{ha}^{-1}\right)$ aproximou-se bastante daquela apresentada por Freitas et al. (2000) em áreas cultivadas do cerrado (81,9 t ha-1), cultura do feijão manejado no sistema convencional de longa duração $\left(84,4 \mathrm{t} \mathrm{ha}^{-1}\right)$ e cultura de milho sob sistema plantio direto $\left(82,5 \mathrm{t} \mathrm{ha}^{-1}\right)$. Entretanto, a média do estoque de CO na EL (93,5 t ha-1, 0-40 cm) foi superior às apresentadas por Freitas et al. (2000). D'Andréa et al. (2004), trabalhando com amostras de Latossolo Vermelho distrófico submetido a seis sistemas de manejo no sul do Estado de Goiás, relataram valores de estoques de $\mathrm{CO}$ acumulado na camada de $0-40 \mathrm{~cm}$ variando de $58,7 \mathrm{t} \mathrm{ha}^{-1}$ (sistema plantio convencional de longa duração) a 69,8 t ha-1 (pastagem), sendo esses resultados inferiores aos verificados neste estudo.

A comparação dos resultados obtidos neste estudo com os observados em outros sistemas de manejo do solo indica que o elevado aporte de resíduos culturais na lavoura cafeeira, a reduzida perda de solo por erosão e a ausência ou menor revolvimento do solo podem contribuir para aumentar ou preservar os estoques de CO do solo. Essa afirmação pode ser comprovada pelos resultados apresentados no quadro 1 , onde, na EL (local de acúmulo dos resíduos vegetais), o $\mathrm{CO}$ acumulado 
Quadro 1. Estoques de carbono (CO) e nitrogênio total (NT) de um Latossolo Vermelho distroférrico típico cultivado com cafeeiro em diferentes espaçamentos de plantio, no Sul de Minas Gerais

\begin{tabular}{|c|c|c|c|c|c|c|c|}
\hline \multirow{2}{*}{ Profundidade } & \multirow{2}{*}{ Espaçamento } & \multicolumn{2}{|c|}{ Estoque de CO } & \multirow{2}{*}{$\begin{array}{c}\text { Estoque total } \\
\text { de CO }\end{array}$} & \multicolumn{2}{|c|}{ Estoque de NT } & \multirow{2}{*}{$\begin{array}{c}\text { Estoque total } \\
\text { de NT }\end{array}$} \\
\hline & & EL & $\mathbf{P C}$ & & EL & $\mathbf{P C}$ & \\
\hline \multirow[t]{6}{*}{$\mathrm{cm}$} & $\mathrm{m}$ & & 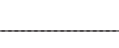 & tha & & & $\bar{U}$ \\
\hline & Mata & & 29,6 & ,4) & & $2,6(=$ & \\
\hline & $2 \times 0,5$ & $21,9 \mathrm{Ca}$ & $19,5 \mathrm{Ba}$ & $20,5 \mathrm{C}$ & $2,2 \mathrm{Ca}$ & $1,8 \mathrm{Aa}$ & $2,0 \mathrm{C}$ \\
\hline & $2 \times 0,75$ & $25,4 \mathrm{Ba}$ & $22,4 \mathrm{Aa}$ & $23,6 \mathrm{~B}$ & $2,2 \mathrm{Ca}$ & $1,9 \mathrm{Aa}$ & $2,0 \mathrm{C}$ \\
\hline & $2 \times 1$ & $21,5 \mathrm{Ca}$ & $19,3 \mathrm{Ba}$ & $20,2 \mathrm{C}$ & $1,7 \mathrm{Ca}$ & $1,7 \mathrm{Aa}$ & $1,7 \mathrm{C}$ \\
\hline & $2,5 \times 0,5$ & $26,3 \mathrm{Ba}$ & $22,7 \mathrm{Ab}$ & $24,6 \mathrm{~B}$ & $2,3 \mathrm{Ca}$ & $1,9 \mathrm{Aa}$ & $2,1 \mathrm{C}$ \\
\hline \multirow[t]{13}{*}{$0-10$} & $2,5 \times 0,75$ & $25,1 \mathrm{Ba}$ & $19,4 \mathrm{Bb}$ & $22,4 \mathrm{C}$ & $2,9 \mathrm{Ba}$ & $2,0 \mathrm{Ab}$ & $2,5 \mathrm{~B}$ \\
\hline & $2,5 \times 1$ & $22,2 \mathrm{Ca}$ & $19,7 \mathrm{Bb}$ & $21,0 \mathrm{C}$ & $2,6 \mathrm{Ba}$ & $2,1 \mathrm{Aa}$ & $2,4 \mathrm{~B}$ \\
\hline & $3 \times 0,5$ & $25,3 \mathrm{Ba}$ & $24,8 \mathrm{Aa}$ & $25,1 \mathrm{~B}$ & $2,9 \mathrm{Ba}$ & $2,4 \mathrm{Aa}$ & $2,7 \mathrm{~B}$ \\
\hline & $3 \times 0,75$ & $25,0 \mathrm{Ba}$ & $20,3 \mathrm{Bb}$ & $23,1 \mathrm{~B}$ & $3,1 \mathrm{Ba}$ & $2,1 \mathrm{Ab}$ & $2,7 \mathrm{~B}$ \\
\hline & $3 \times 1$ & $21,3 \mathrm{Ca}$ & $19,5 \mathrm{Ba}$ & $20,6 \mathrm{C}$ & $3,0 \mathrm{Ba}$ & $2,1 \mathrm{Ab}$ & $2,6 \mathrm{~B}$ \\
\hline & $3,5 \times 0,5$ & $31,4 \mathrm{Aa}$ & $23,0 \mathrm{Ab}$ & $28,5 \mathrm{~A}$ & $3,2 \mathrm{Ba}$ & $2,5 \mathrm{Aa}$ & $3,0 \mathrm{~B}$ \\
\hline & $3,5 \times 0,75$ & $21,8 \mathrm{Ca}$ & $17,2 \mathrm{Bb}$ & $20,2 \mathrm{C}$ & $2,2 \mathrm{Ca}$ & $1,9 \mathrm{Aa}$ & $2,1 \mathrm{C}$ \\
\hline & $3,5 \times 1$ & $31,7 \mathrm{Aa}$ & $23,3 \mathrm{Ab}$ & $28,8 \mathrm{~A}$ & $4,3 \mathrm{Aa}$ & $2,1 \mathrm{Ab}$ & $3,5 \mathrm{~A}$ \\
\hline & Mata & & 30,7 & ,2) & & 2,5 & \\
\hline & $2 \times 0,5$ & $24,1 \mathrm{Aa}$ & $29,8 \mathrm{Aa}$ & $27,5 \mathrm{~A}$ & $2,2 \mathrm{Aa}$ & $2,4 \mathrm{Aa}$ & $2,3 \mathrm{~A}$ \\
\hline & $2 \times 0,75$ & $22,5 \mathrm{Aa}$ & $21,4 \mathrm{Aa}$ & $21,8 \mathrm{~A}$ & $2,5 \mathrm{Aa}$ & $2,4 \mathrm{Aa}$ & $2,4 \mathrm{~A}$ \\
\hline & $2 \times 1$ & $23,7 \mathrm{Aa}$ & $25,5 \mathrm{Aa}$ & $24,8 \mathrm{~A}$ & $2,5 \mathrm{Aa}$ & $2,6 \mathrm{Aa}$ & $2,6 \mathrm{~A}$ \\
\hline & $2,5 \times 0,5$ & $26,4 \mathrm{Aa}$ & $27,1 \mathrm{Aa}$ & $26,7 \mathrm{~A}$ & $2,9 \mathrm{Aa}$ & $2,8 \mathrm{Aa}$ & $2,8 \mathrm{~A}$ \\
\hline \multirow[t]{13}{*}{$10-20$} & $2,5 \times 0,75$ & $25,5 \mathrm{Aa}$ & $21,1 \mathrm{Aa}$ & $23,4 \mathrm{~A}$ & $2,0 \mathrm{Aa}$ & $1,9 \mathrm{Aa}$ & $1,9 \mathrm{~A}$ \\
\hline & $2,5 \times 1$ & $25,7 \mathrm{Aa}$ & $23,8 \mathrm{Aa}$ & $24,8 \mathrm{~A}$ & $2,5 \mathrm{Aa}$ & $2,4 \mathrm{Aa}$ & $2,4 \mathrm{~A}$ \\
\hline & $3 \times 0,5$ & $30,3 \mathrm{Aa}$ & $25,8 \mathrm{Aa}$ & $28,5 \mathrm{~A}$ & $3,0 \mathrm{Aa}$ & $2,1 \mathrm{Aa}$ & $2,6 \mathrm{~A}$ \\
\hline & $3 \times 0,75$ & $20,9 \mathrm{Aa}$ & $16,3 \mathrm{Aa}$ & $19,1 \mathrm{~A}$ & $1,9 \mathrm{Aa}$ & $1,5 \mathrm{Aa}$ & $1,7 \mathrm{~A}$ \\
\hline & $3 \times 1$ & $30,4 \mathrm{Aa}$ & $23,7 \mathrm{Aa}$ & $27,7 \mathrm{~A}$ & $2,4 \mathrm{Aa}$ & $1,9 \mathrm{Aa}$ & $2,2 \mathrm{~A}$ \\
\hline & $3,5 \times 0,5$ & $22,0 \mathrm{Aa}$ & $22,2 \mathrm{Aa}$ & $22,1 \mathrm{~A}$ & $2,1 \mathrm{Aa}$ & $2,8 \mathrm{Aa}$ & $2,3 \mathrm{~A}$ \\
\hline & $3,5 \times 0,75$ & $27,3 \mathrm{Aa}$ & $22,8 \mathrm{Aa}$ & $25,7 \mathrm{~A}$ & $3,1 \mathrm{Aa}$ & $2,5 \mathrm{Aa}$ & $2,9 \mathrm{~A}$ \\
\hline & $3,5 \times 1$ & $24,2 \mathrm{Aa}$ & $20,8 \mathrm{Aa}$ & $23,0 \mathrm{~A}$ & $2,1 \mathrm{Aa}$ & $2,7 \mathrm{Aa}$ & $2,3 \mathrm{~A}$ \\
\hline & Mata & & 43,2 & ,9) & & $4,3($ & \\
\hline & $2 \times 0,5$ & $41,7 \mathrm{Aa}$ & $39,3 \mathrm{Aa}$ & $40,3 \mathrm{~A}$ & $4,8 \mathrm{Aa}$ & $4,4 \mathrm{Aa}$ & $4,6 \mathrm{~A}$ \\
\hline & $2 \times 0,75$ & $45,0 \mathrm{Aa}$ & $43,0 \mathrm{Aa}$ & $43,8 \mathrm{~A}$ & $5,0 \mathrm{Aa}$ & $4,7 \mathrm{Aa}$ & $4,8 \mathrm{~A}$ \\
\hline & $2 \times 1$ & $35,4 \mathrm{Ba}$ & $37,7 \mathrm{Aa}$ & $36,8 \mathrm{~B}$ & $4,3 \mathrm{Ba}$ & $3,6 \mathrm{Ba}$ & $3,9 \mathrm{~B}$ \\
\hline & $2,5 \times 0,5$ & $45,7 \mathrm{Aa}$ & $40,3 \mathrm{Ab}$ & $43,1 \mathrm{~A}$ & $4,1 \mathrm{Ba}$ & $4,0 \mathrm{Ba}$ & $4,0 \mathrm{~B}$ \\
\hline \multirow[t]{13}{*}{$20-40$} & $2,5 \times 0,75$ & $47,8 \mathrm{Ba}$ & $37,7 \mathrm{Ab}$ & $42,9 \mathrm{~A}$ & $4,8 \mathrm{Aa}$ & $3,9 \mathrm{Bb}$ & $4,4 \mathrm{~A}$ \\
\hline & $2,5 \times 1$ & $39,7 \mathrm{Ba}$ & $44,0 \mathrm{Ab}$ & $41,8 \mathrm{~A}$ & $4,4 \mathrm{Ba}$ & $4,5 \mathrm{Aa}$ & $4,5 \mathrm{~A}$ \\
\hline & $3 \times 0,5$ & $47,7 \mathrm{Aa}$ & $40,0 \mathrm{Ab}$ & $44,6 \mathrm{~A}$ & $4,5 \mathrm{Aa}$ & $4,2 \mathrm{Aa}$ & $4,4 \mathrm{~A}$ \\
\hline & $3 \times 0,75$ & $41,7 \mathrm{Aa}$ & $41,3 \mathrm{Aa}$ & $41,5 \mathrm{~A}$ & $4,0 \mathrm{Ba}$ & $4,3 \mathrm{Aa}$ & $4,1 \mathrm{~B}$ \\
\hline & $3 \times 1$ & $37,0 \mathrm{Ba}$ & $37,4 \mathrm{Aa}$ & $37,2 \mathrm{~B}$ & $3,8 \mathrm{Ba}$ & $3,6 \mathrm{Ba}$ & $3,7 \mathrm{~B}$ \\
\hline & $3,5 \times 0,5$ & $47,0 \mathrm{Aa}$ & $35,7 \mathrm{Ab}$ & $43,1 \mathrm{~A}$ & $5,0 \mathrm{Aa}$ & $3,6 \mathrm{Bb}$ & $4,5 \mathrm{~A}$ \\
\hline & $3,5 \times 0,75$ & $45,4 \mathrm{Aa}$ & $38,7 \mathrm{Ab}$ & $43,1 \mathrm{~A}$ & $4,6 \mathrm{Aa}$ & $4,2 \mathrm{Aa}$ & $4,5 \mathrm{~A}$ \\
\hline & $3,5 \times 1$ & $44,0 \mathrm{Aa}$ & $34,7 \mathrm{Ab}$ & $40,8 \mathrm{~A}$ & $4,0 \mathrm{Ba}$ & $3,9 \mathrm{Ba}$ & $4,0 \mathrm{~B}$ \\
\hline & Mata & & 103,6 & $6,5)$ & & 8,3 & \\
\hline & $2 \times 0,5$ & $89,6 \mathrm{Ba}$ & $88,6 \mathrm{Aa}$ & $89,0 \mathrm{~B}$ & $9,3 \mathrm{Ba}$ & $8,6 \mathrm{Aa}$ & $8,9 \mathrm{~B}$ \\
\hline & $2 \times 0,75$ & $92,8 \mathrm{Ba}$ & $86,5 \mathrm{Aa}$ & $89,0 \mathrm{~B}$ & $9,6 \mathrm{Ba}$ & $9,0 \mathrm{Aa}$ & $9,2 \mathrm{~A}$ \\
\hline & $2 \times 1$ & $80,6 \mathrm{Ba}$ & $82,5 \mathrm{Ba}$ & $81,7 \mathrm{C}$ & $8,5 \mathrm{Ba}$ & $7,9 \mathrm{Ba}$ & $8,1 \mathrm{~B}$ \\
\hline & $2,5 \times 0,5$ & $98,6 \mathrm{Aa}$ & $90,2 \mathrm{Aa}$ & $94,6 \mathrm{~A}$ & $9,4 \mathrm{Ba}$ & $8,8 \mathrm{Aa}$ & $9,1 \mathrm{~A}$ \\
\hline \multirow[t]{8}{*}{$0-40$} & $2,5 \times 0,75$ & $98,2 \mathrm{Aa}$ & $78,5 \mathrm{Bb}$ & $88,7 \mathrm{~B}$ & $9,7 \mathrm{Ba}$ & $7,8 \mathrm{Bb}$ & $8,8 \mathrm{~B}$ \\
\hline & $2,5 \times 1$ & $87,6 \mathrm{Ba}$ & $87,7 \mathrm{Aa}$ & $87,6 \mathrm{~B}$ & $9,5 \mathrm{Ba}$ & $9,0 \mathrm{Aa}$ & $9,6 \mathrm{~A}$ \\
\hline & $3 \times 0,5$ & $103,3 \mathrm{Aa}$ & $90,7 \mathrm{Ab}$ & $98,3 \mathrm{~A}$ & $10,4 \mathrm{Aa}$ & $8,8 \mathrm{Ab}$ & $9,8 \mathrm{~A}$ \\
\hline & $3 \times 0,75$ & $87,5 \mathrm{Ba}$ & $77,8 \mathrm{Ba}$ & $83,6 \mathrm{C}$ & $9,1 \mathrm{Ba}$ & $8,0 \mathrm{Ba}$ & $8,7 \mathrm{~B}$ \\
\hline & $3 \times 1$ & $88,6 \mathrm{Ba}$ & $80,7 \mathrm{Ba}$ & $85,4 \mathrm{~B}$ & $9,2 \mathrm{Ba}$ & $7,7 \mathrm{Bb}$ & $8,6 \mathrm{~B}$ \\
\hline & $3,5 \times 0,5$ & $100,0 \mathrm{Aa}$ & $81,0 \mathrm{Bb}$ & $93,5 \mathrm{~A}$ & $10,3 \mathrm{Aa}$ & $9,0 \mathrm{Ab}$ & $9,8 \mathrm{~A}$ \\
\hline & $3,5 \times 0,75$ & $94,7 \mathrm{Aa}$ & $78,7 \mathrm{Bb}$ & $89,2 \mathrm{~B}$ & $10,0 \mathrm{Aa}$ & $8,5 \mathrm{Ab}$ & $9,5 \mathrm{~A}$ \\
\hline & $3,5 \times 1$ & $100,2 \mathrm{Aa}$ & $78,7 \mathrm{Bb}$ & $92,8 \mathrm{~A}$ & $10,5 \mathrm{Aa}$ & $9,0 \mathrm{Ab}$ & $10,0 \mathrm{~A}$ \\
\hline
\end{tabular}

Valores entre parênteses referem-se ao erro-padrão da média $(\mathrm{n}=3)$. Médias seguidas por letras minúsculas iguais na linha e maiúsculas iguais na coluna não diferem entre si pelo teste Scott-Knott $(p<0,05)$. Os valores dos estoques totais de C e NT equivalem à média ponderada entre os resultados obtidos na EL e na PC dos cafeeiros. EL: amostras coletadas nas entrelinhas; PC: amostras coletadas na projeção das copas dos cafeeiros. 
na camada de $0-40 \mathrm{~cm}$ nos espaçamentos de $3,0 \times 0,5$ $3,5 \times 0,5 ; 3,5 \times 0,75 ; 3,5 \times 1,0 ; 2,5 \times 0,5$ e $2,5 \times 0,75 \mathrm{~m}$ esteve próximo do CO armazenado na área de mata. Nesta camada de solo, a redução média do estoque de CO foi de cerca de $10 \%$, para as amostras coletadas na EL, e de cerca de $20 \%$, para aquelas coletadas na $\mathrm{PC}$, em relação à área de mata. Ainda, na camada de 0-40 cm, o estoque de CO na EL foi, em média, $12 \%$ superior ao da PC, o que equivale a $10 \mathrm{t} \mathrm{ha}^{-1}$ a mais de CO armazenado na EL do cafeeiro.

$\mathrm{Na}$ camada superficial do solo $(0-10 \mathrm{~cm})$, os estoques de $\mathrm{CO}$ na $\mathrm{EL}$ foram maiores nos espaçamentos de $3,5 \times 0,5 \mathrm{~m}$ (5.714 plantas ha $\left.{ }^{-1}\right) \mathrm{e}$ $3,5 \times 1 \mathrm{~m}$ (2.857 plantas ha ${ }^{-1}$ ) (Quadro 1), indicando a ausência de efeito da população de plantas sobre o CO armazenado nesta camada de solo. Esses dados indicam a possibilidade de armazenar no solo as mesmas quantidades de $\mathrm{CO}$ quando se adotam diferentes combinações de espaçamentos entre ruas e entre plantas nas lavouras cafeeiras. Na PC, os maiores estoques de $\mathrm{CO}$ foram verificados nos tratamentos que possuíam 6.666 ( 2 x 0,75 e $3 \times 0,5 \mathrm{~m})$, $8.000(2,5 \times 0,5 \mathrm{~m}), 5.714(3,5 \times 0,5 \mathrm{~m})$ e, a exceção, $2.857(3,5 \times 1 \mathrm{~m})$ plantas por hectare. Uma das possíveis explicações para o maior estoque de CO na EL, em tratamentos com menor população de plantas, é a relacionada ao maior aporte de resíduos de plantas daninhas presentes na entrelinha desses tratamentos, compensando a menor quantidade de resíduos vegetais depositados nas ruas de cafeeiro. Segundo Boddey et al. (2001) e Pillon et al. (2001), as plantas invasoras apresentam alta taxa de renovação do sistema radicular, elevada alocação de fotossintatos e altos teores de lignina nas raízes e maior grau de humificação do $\mathrm{C}$ adicionado, o que pode contribuir para maior preservação ou aumento da MOS. Não se pode descartar também a possibilidade de ter havido maior produção de biomassa pelas plantas de cafeeiro nos sistemas menos adensados, o que aumentaria o aporte de $\mathrm{C}$ ao solo.

A introdução de menores espaçamentos de plantio parece exercer pequeno efeito nos estoques de NT na camada superficial do solo $(0-10 \mathrm{~cm})$ (Quadro 1$)$. Na $\mathrm{PC}$, os estoques de NT não diferiram entre si nos diferentes espaçamentos de plantio, sendo notada tendência de aumento no $\mathrm{N}$ armazenado no solo com o incremento do espaçamento entre linhas de plantio (1,7 e 2,5 t ha-1, para os espaçamentos entre linhas de 2 e $3,5 \mathrm{~m}$, nesta ordem). Na EL, os menores estoques de NT foram observados nos menores espaçamentos entre linhas de plantio (2 e $2,5 \mathrm{~m})$. Entre os pontos de coleta das amostras de solo, na camada de 0-10 cm, os maiores estoques de NT foram observados na EL, nos espaçamentos de 2,5 x 0,75, 3 x 0,75, 3 x 1 e 3,5 x $1 \mathrm{~m}$, com valores superiores ao observado na área de mata.

Os estoques de NT também foram maiores no solo sob mata, quando comparados ao solo da EL e da PC do cafeeiro. Na camada de $0-20 \mathrm{~cm}(0-10+10-20 \mathrm{~cm})$, as perdas de NT na EL e na PC foram, respectiva- mente, de 19 e 36,2 \%, indicando menores perdas nos ambientes com maior aporte de resíduos vegetais. Num Argissolo Vermelho-Amarelo submetido a diferentes sistemas de produção (mineral e orgânica), Leite et al. (2003) observaram reduções no estoque de NT de $37 \%$ na testemunha (sem adubação) e de 15,4\% no sistema com adubação orgânica, em relação ao sistema referência (floresta nativa), indicando a menor perda de $\mathrm{N}$ no sistema com maior aporte de matéria orgânica, resultados que concordam com os dados apresentados neste estudo.

Os dados relativos aos estoques totais de CO e NT, que foram calculados considerando os estoques determinados na PC e na EL e suas respectivas áreas de abrangência em cada tratamento, são também apresentados no quadro 1. Em relação à área de mata, o cultivo do cafeeiro, dependendo do espaçamento de plantio adotado, causou reduções nos estoques totais de CO do solo (0-40 cm), que variaram de 5,1 a 21,1\%, com média de $13,6 \%$. Os estoques totais de $\mathrm{CO}$ no solo $(0-40 \mathrm{~cm})$ variaram de 81,7 a $98,3 \mathrm{t} \mathrm{ha}^{-1}$. ̀̀ exceção dos espaçamentos de 3,5 x 1 e 2 x 0,5 m, na camada de solo de 0-40 cm, os maiores estoques totais de CO foram observados nas parcelas em que a distância entre uma planta e outra de cafeeiro era de $0,5 \mathrm{~m}$, independentemente da distância entre as fileiras. Os estoques totais de NT variaram, na profundidade de solo de $0-40 \mathrm{~cm}$, de 8,1 a $10 \mathrm{t} \mathrm{ha}^{-1}$, sendo notada tendência de maior armazenamento de $\mathrm{N}$ nas áreas onde a distância entre fileiras de cafeeiro era de 3,5 m. Esses dados indicam que, ao calcular os estoques de $\mathrm{CO}$ em lavouras cafeeiras, é preciso considerar os espaçamentos entre fileiras e entre plantas e as quantidades de $\mathrm{C}$ e $\mathrm{N}$ presentes na entrelinha e na projeção da copa e suas respectivas áreas de abrangência na lavoura.

A relação entre a área ocupada por planta e os estoques de CO e NT, na profundidade de solo de 0-40 cm, é apresentada na figura 1 . A variação na área ocupada pelo cafeeiro não exerceu influência sobre as quantidades de $\mathrm{C}$ e $\mathrm{N}$ armazenadas no solo. Isso demonstra que o adensamento da lavoura cafeeira pode não resultar em acréscimo no estoque de matéria orgânica do solo. Esses resultados não concordam com os dados obtidos por Pavan et al. (1999), que constataram acréscimo de $31 \%$ nos teores de $\mathrm{C}$ do solo $(0-20 \mathrm{~cm})$ da entrelinha quando a população de cafeeiro aumentou de 893 para 7.143 plantas ha ${ }^{-1}$. Esse acréscimo nos teores de $\mathrm{CO}$ foram atribuídos ao maior controle da erosão, à melhoria no manejo de resíduos e na ciclagem de nutrientes e à redução da lixiviação. De fato, a comparação de resultados é dificultada em razão de o estudo citado ter sido desenvolvido em Londrina, PR. Desse modo, há grande chance de as condições climáticas, as práticas culturais, o tipo de solo, os níveis de produtividade do cafeeiro, o aporte de resíduos vegetais, as perdas de solo por erosão etc. serem bastante distintos em relação às condições predominantes no Sul de Minas Gerais. 


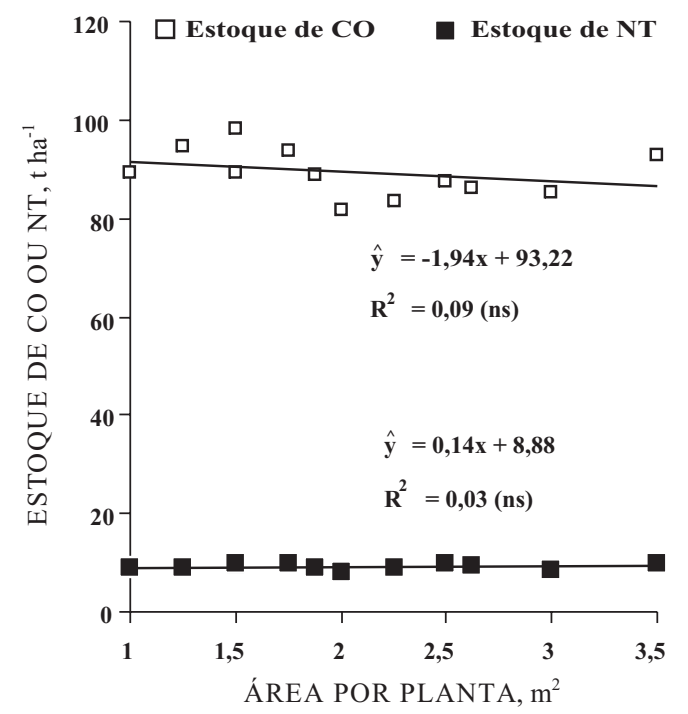

Figura 1. Relação entre a área ocupada por planta e o estoque de carbono orgânico $(\mathrm{CO})$ e de nitrogênio total (NT) na camada de solo de 0$40 \mathrm{~cm}$. ns, não-significativo.

\section{Fracionamento físico-densimétrico da matéria orgânica do solo}

A distribuição do $\mathrm{C}$ orgânico nas frações leve $\left(\mathrm{C}_{\mathrm{FL}}\right)$ e pesada $\left(\mathrm{C}_{\mathrm{FP}}\right)(\mathrm{C}$ associado à fração areia, $\mathrm{C}$-areia; $\mathrm{C}$ associado à fração silte, $\mathrm{C}$-silte; $\mathrm{C}$ associado à fração argila, C-argila) da matéria orgânica de Latossolo Vermelho distroférrico típico cultivado com cafeeiro, em diferentes espaçamentos de plantio, é mostrada na figura 2. Os índices de recuperação do $\mathrm{C}$ nas diferentes frações variaram de 86 a $114 \%$ e de 87 a $110 \%$ do total de CO do solo, nas profundidades de 0-5 e 0-10 cm, respectivamente, estando esses valores dentro da faixa considerada adequada para esse tipo de estudo (Freixo et al., 2002a).

Em relação aos teores de C-FL, as maiores diferenças entre os pontos de coleta das amostras de solo ocorreram na profundidade de $0-5 \mathrm{~cm}$, indicando a maior presença desta fração na camada mais superficial do solo, onde são depositados os resíduos vegetais (Figura 2). Nas duas profundidades avaliadas, os maiores teores de $\mathrm{C}_{\mathrm{FL}}$ foram observados no espaçamento de $3,5 \times 1 \mathrm{~m}$, com valores superiores aos observados na área de mata. Um aspecto importante a ser destacado é que o adensamento da lavoura cafeeira reduziu os teores de C-FL, principalmente nas amostras coletadas na EL. Assim, o acréscimo nos teores de C-FL em ruas mais largas de cafeeiro pode estar associado a uma possível maior presença de plantas invasoras (gramíneas) nas entrelinhas dos tratamentos com menor estande de plantas $(3 \times 0,75,3,5 \times 0,75$ e $3,5 \times 1 \mathrm{~m})$. Essas plantas, por apresentarem alta taxa de renovação de seu sistema radicular, podem ter contribuído para aumentar os teores de $\mathrm{C}_{\mathrm{FL}}$ na EL.
A maior parte do $\mathrm{CO}$ esteve associada à fração pesada, que respondeu, em média, por 92 e $93 \%$ do CO do solo sob mata, nas profundidades de solo de $0-5$ e $0-10 \mathrm{~cm}$, respectivamente (Figura 2). $\mathrm{O}$ cultivo do solo proporcionou aumento relativo de $\mathrm{C}_{\mathrm{FP}}$, principalmente nas amostras coletadas na $\mathrm{PC}$, onde o $\mathrm{C}_{\mathrm{FP}}$ representou de 92 a $97 \%$ do $\mathrm{CO}$ do solo na profundidade de $0-5 \mathrm{~cm}$ e de 97 a $99 \%$ na profundidade de $0-10 \mathrm{~cm}$.

A retirada da vegetação natural e o cultivo do cafeeiro promoveram alterações na distribuição relativa do $\mathrm{CO}$ nas frações granulométricas do solo (Figura 2). Na profundidade de solo de $0-5 \mathrm{~cm}$, na EL, ocorreu acréscimo relativo de CO na fração areia e empobrecimento relativo nos teores desse elemento nas frações argila e silte. De acordo com Feller \& Beare (1997), em solos argilosos cultivados, a diminuição do reservatório de $\mathrm{C}$ relaciona-se, principalmente, com a decomposição de frações orgânicas lábeis associadas à argila. Em contrapartida, na PC, essa distribuição apresentou comportamento diferente do relatado para a EL, ou seja, maiores proporções do CO nas frações argila e silte, e redução proporcional de CO na fração areia. Aumentos acentuados nas proporções de CO nas frações areia, silte e argila, tanto na EL como na PC, foram os principais efeitos associados à retirada da vegetação nativa e ao cultivo de cafeeiro, na profundidade de solo de 0-10 cm (Figura 3).

Em estudo sobre a distribuição do $\mathrm{CO}$ em diferentes frações granulométricas de Latossolos da região de Cerrado, Silva et al. (1999) também verificaram enriquecimento relativo de $\mathrm{CO}$ nas frações granulométricas mais finas (silte e argila) devido ao cultivo do solo, o que está de acordo com os dados deste estudo (Figura 3). Em locais onde predominam a remoção intensiva de resíduos vegetais da área de plantio e o preparo excessivo do solo, as perdas de $\mathrm{C}$ do sistema solo-planta são dependentes, na maioria das vezes, do aumento da taxa de mineralização das frações menos decompostas associadas, principalmente, à areia (Guggenberger et al., 1994; Silva et al., 1999). Assim, a redução na proporção de $\mathrm{CO}$ associado à fração areia observada na PC $(0-5 \mathrm{~cm})$ pode ser atribuída ao menor aporte de resíduos vegetais ao solo nesse local.

Em termos gerais, os reservatórios de $\mathrm{CO}$ associados à areia foram muito baixos, perfazendo menos de $10 \%$ dos teores totais de $\mathrm{C}$ nos diferentes espaçamentos de plantio estudados, o que concorda com os resultados obtidos por Silva et al. (1999). Apesar de contribuir com pequena parte da matéria orgânica presente nos solos, é à areia que se associam as frações orgânicas de maior biodisponibilidade, em relação àquelas ligadas às frações argila e silte (Christensen, 1996). Esse fato se deve ao processo de separação da areia das demais partículas texturais, uma vez que, durante a dispersão dos solos, mais especificamente na etapa de peneiramento úmido, agrega-se à areia material orgânico particulado, com 

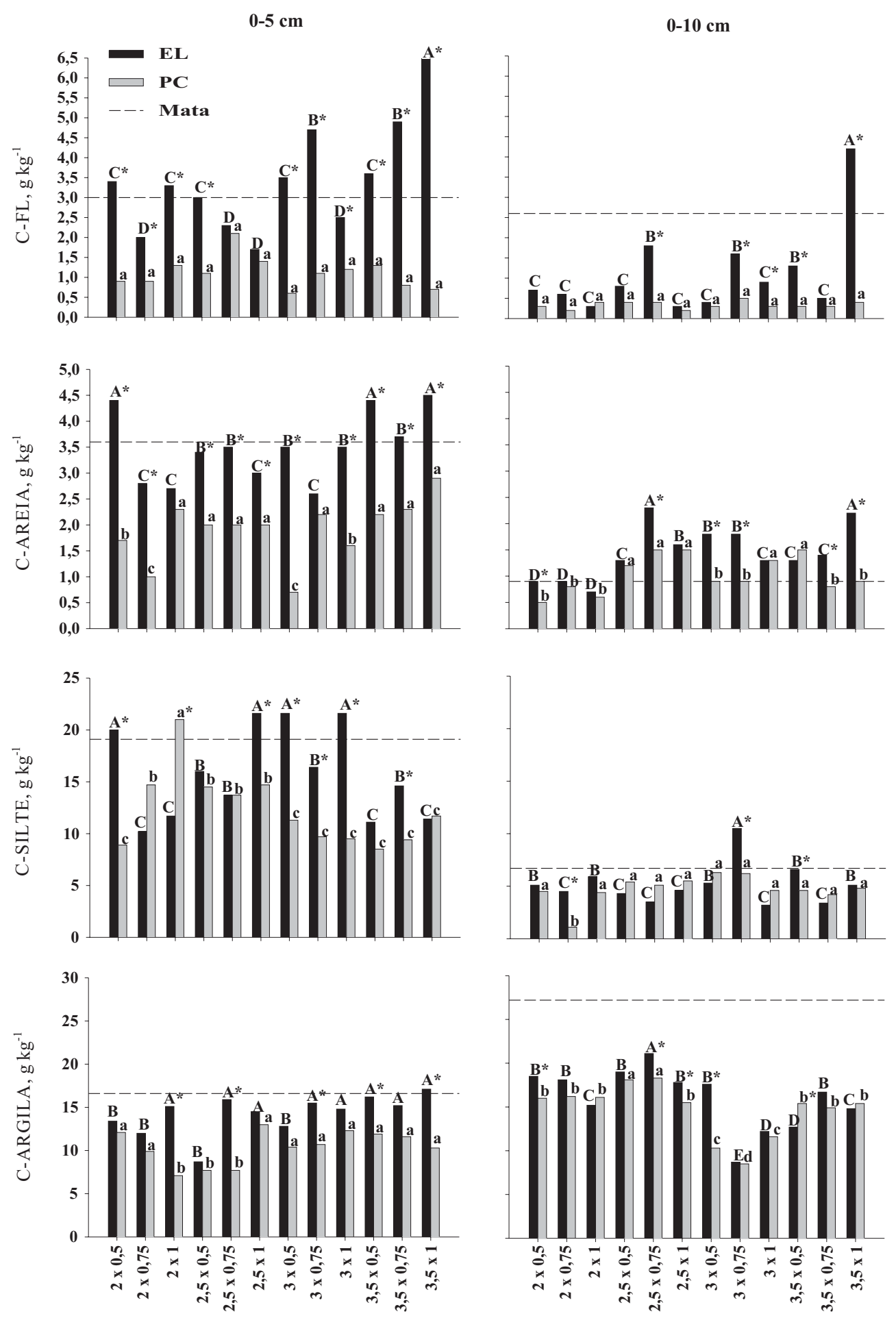

ESPAÇAMENTO DE PLANTIO, $\mathrm{m}$

Figura 2. Teores de $C$ nas frações leve $\left(C_{F L}\right)$, areia (C-areia), silte (C-silte) e argila (C-argila) sob influência de diferentes espaçamentos de plantio de cafeeiro cultivado em um Latossolo Vermelho distroférrico. EL: amostras coletadas na entrelinha; PC: amostras coletadas na projeção da copa. Letras maiúsculas compararam os teores de carbono entre os diferentes espaçamentos de plantio, para as amostras coletadas na EL. Letras minúsculas compararam os teores de carbono entre os diferentes espaçamentos de plantio, para as amostras coletadas na PC. Médias seguidas da mesma letra não diferem entre si pelo teste de Scott-Knott (p < 0,05). *Compara os teores de C entre os locais de coleta de amostras (EL e PC), dentro de cada espaçamento de plantio. A presença do * designa média estatisticamente superior pelo teste F a $5 \%$. 


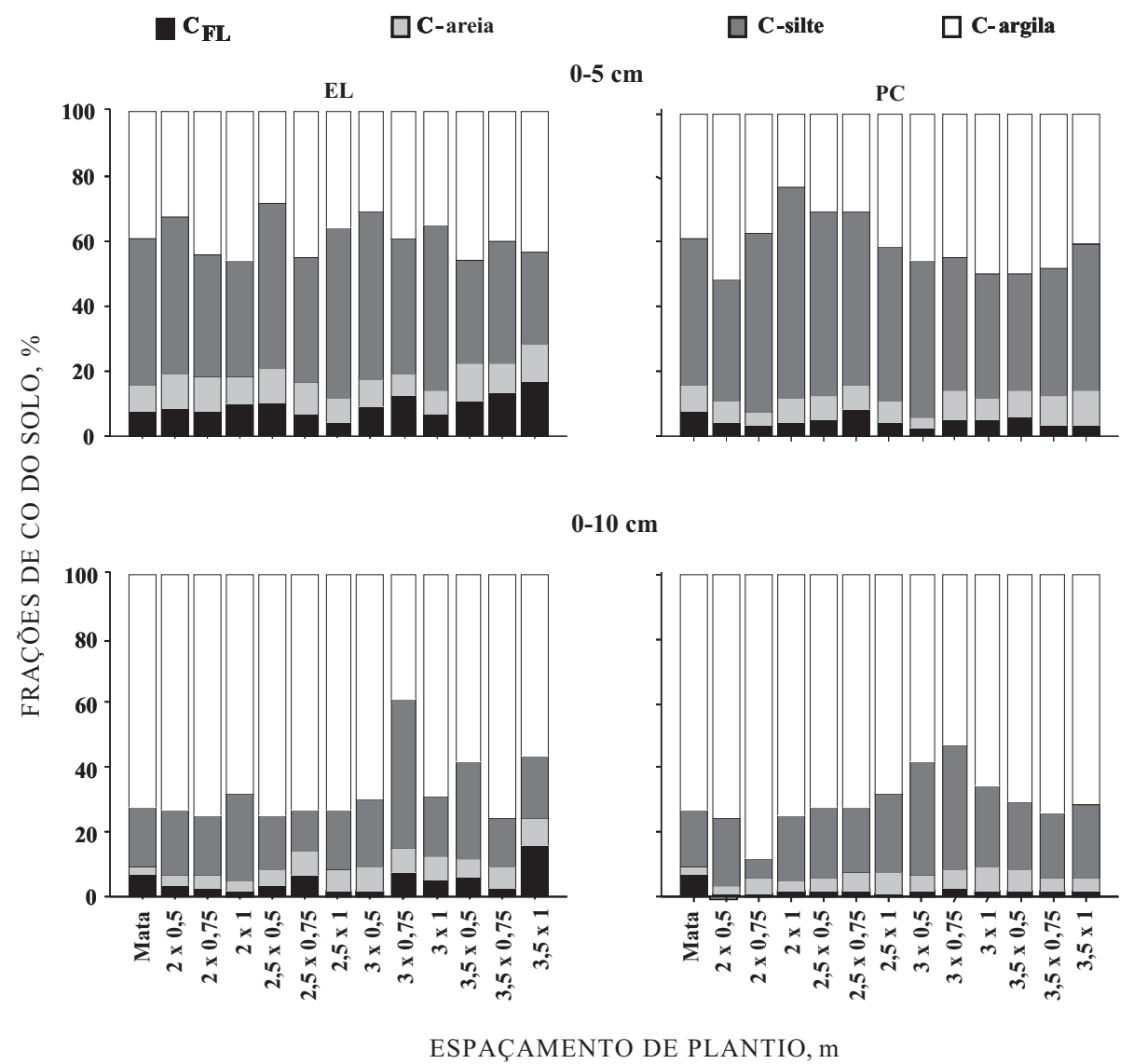

Figura 3. Percentagem do carbono orgânico nas frações leve $\left(\mathrm{C}_{\mathrm{FL}}\right)$ e pesada (C-areia, $\mathrm{C}$-silte e $\mathrm{C}$-argila) da matéria orgânica, nas profundidades de 0-5 e 0-10 cm de um Latossolo Vermelho distroférrico típico cultivado com cafeeiro em diferentes espaçamentos de plantio. EL: amostras coletadas na entrelinha; PC: amostras coletadas na projeção da copa.

grau de decomposição mais próximo ao de resíduos vegetais recentemente adicionados aos solos. Por sua vez, a retirada do $\mathrm{C}$ associado à fração leve da MOS pode causar redução na biodisponibilidade da MOS associada à areia. Não se pode descartar também a presença na fração areia de material recalcitrante remanescente de queimadas ou de $\mathrm{C}$ associado a argila e silte, que, agrupados em solo, se comportam, em termos de tamanho, como a fração areia. À argila e, em menor intensidade, ao silte ligam-se compostos de relação $\mathrm{C} / \mathrm{N}$ baixa e de maior estabilidade química, normalmente resultantes do metabolismo de microrganismos (Christensen, 1996).

Em resumo, os principais efeitos do cultivo em diferentes espaçamentos do cafeeiro, provavelmente, se relacionam à redução nos teores absolutos de $\mathrm{CO}$ associados à areia e às frações mais finas (argila e silte) (Figura 2) e a um enriquecimento relativo (Figura 3) desse elemento nessas duas últimas frações, principalmente na EL $(0-10 \mathrm{~cm})$.

$\mathrm{Na}$ figura 4 são apresentados os aumentos e as reduções percentuais nos teores de $\mathrm{C}$ de diferentes frações e nos estoques de $\mathrm{CO}$ e NT de amostras coletadas na EL e na PC, nos diferentes espaçamentos de plantio do cafeeiro. Os valores obtidos no solo de mata foram utilizados como referência. Verificou-se que as maiores oscilações entre as frações de $\mathrm{C}$ analisadas ocorreram para os teores de $\mathrm{C}_{\mathrm{FL}}(-43 \mathrm{e}+$ $117 \%$ na EL e -30 e - $80 \%$ na PC). Na EL, onde era maior o aporte de resíduos, observou-se aumento médio nos teores de $\mathrm{C}_{\mathrm{FL}}$, em relação ao solo de mata, de $16 \%$, com os maiores incrementos ocorrendo no espaçamento de 3,5 m entre plantas - comportamento diferenciado daquele notado para o $\mathrm{C}_{\mathrm{FP}}$, cujos teores foram reduzidos em todos os espaçamentos avaliados. $\mathrm{Na} \mathrm{PC}$, houve redução em todos os atributos avaliados (Figura 4), indicando a suscetibilidade à decomposição da matéria orgânica em ambientes em que predominam o baixo aporte de resíduos vegetais e o manejo menos conservacionista do solo. Considerando os diferentes espaçamentos de plantio e os pontos de coleta de amostras de solo, a amplitude de variação nos teores de $\mathrm{C}_{\mathrm{FL}}$ foi maior do que as verificadas para o $\mathrm{C}_{\mathrm{FP}}$, EstC e EstN, indicando que o C-FL pode ser utilizado como indicador das mudanças na qualidade da MOS em decorrência da adoção de diferentes sistemas de cultivo na lavoura cafeeira. 
EL
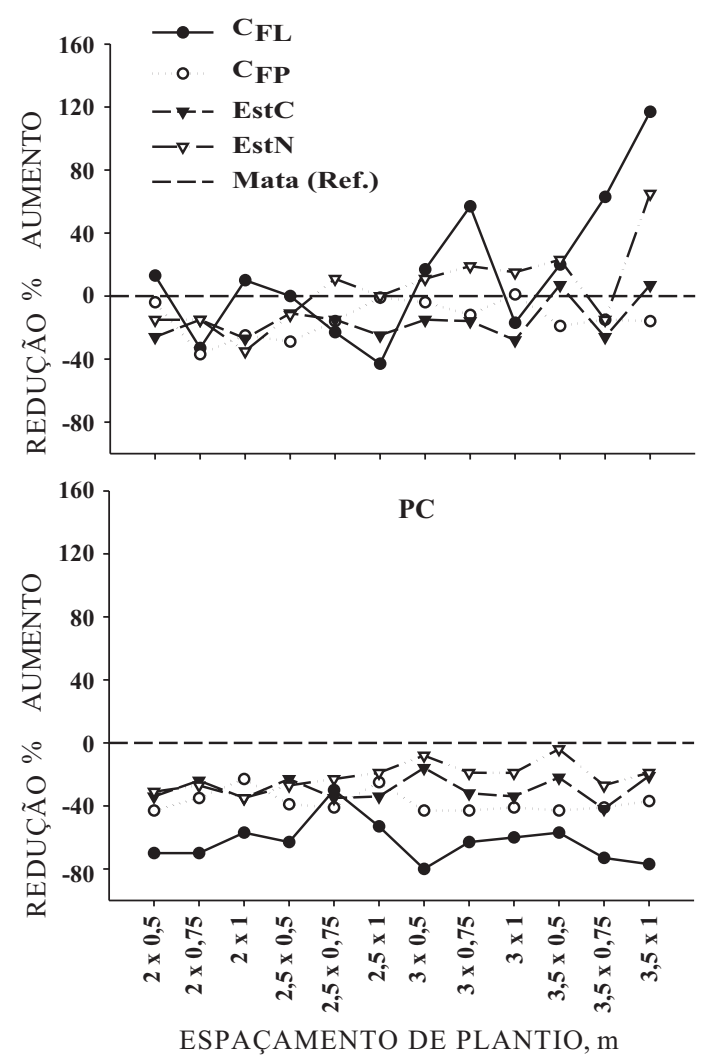

Figura 4. Aumentos ou reduções relativas de Cfração leve, C-fração pesada, estoque de $\mathrm{CO}$ e estoque de NT de um Latossolo Vermelho distroférrico típico cultivado com cafeeiro em diferentes espaçamentos de plantio, considerando como referência os dados desses mesmos atributos obtidos para o solo sob mata (Ref.). EL: amostras coletadas na entrelinha; PC: amostras coletadas na projeção da copa; $\mathrm{C}_{\mathrm{FL}}$ : carbono associado à fração leve; $\mathbf{C}_{\mathrm{FP}}$ : carbono associado à fração pesada $(\mathrm{C}$-areia + C-silte + C-argila); EstC: estoque de CO; EstN: estoque de NT. Os dados de EstC e EstN foram obtidos para as amostras coletadas na profundidade de 0-10 cm; os dados de $C_{F L}$ e $C_{F P}$ referem-se às amostras da profundidade de solo de 0-5 cm.

\section{CONCLUSÕES}

1. Os estoques de $\mathrm{CO}$ e de NT e as outras frações da matéria orgânica do solo avaliadas não são afetados pelo espaçamento entre plantas e entre linhas, pela área de planta e pela população de cafeeiro.

2. Os estoques de $\mathrm{CO}$ e os teores de C-FL na entrelinha do cafeeiro são iguais ou superiores àqueles verificados na projeção da copa.

3. O espaçamento de plantio de cafeeiro de $3,5 \times 1 \mathrm{~m}$ é o que propicia no solo $(0-5$ e $0-10 \mathrm{~cm})$ o maior teor de $\mathrm{C}$ associado à fração leve, na entrelinha.

\section{AGRADECIMENTOS}

À equipe da Estação Experimental da EpamigMachado, MG, em especial ao senhor Gilmar José Cereda, pela ajuda na coleta das amostras e na condução e manutenção do experimento avaliado; ao Consórcio Brasileiro de Pesquisa e Desenvolvimento/ Café, à Embrapa Café (Projeto 19.2003.133.03) e à FAPEMIG (EDT 2222/2003), pela concessão de fomento utilizado no custeio das ações de pesquisa.

\section{LITERATURA CITADA}

ALVAREZ, R. \& LAVADO, R.S. Climatic, organic matter and clay content relationship in the Pampa and Chaco soils, Argentina. Geoderma, 83:127-141, 1998.

BARRIOS, E.; BURESH, R.J. \& SPRENT, J.I. Organic matter in soil particle size and density fractions from maize and legume cropping systems. Soil Biol. Biochem., 28:185193, 1996.

BENITES, V.M.; MENDONÇA, E.S.; SCHAEFFER, C.E.R. \& MARTIN-NETO, L. Caracterização dos ácidos húmicos extraídos de um Latossolo Vermelho-Amarelo e de um Podzol por análise termodiferencial e pela espectroscopia de absorção infravermelho. R. Bras. Ci. Solo, 23:543-551, 1999.

BODDEY, R.M.; ALVES, B.J.R.; OLIVEIRA, O.C. \& URGUIGA, S. Potencial para acumulação e seqüestro de carbono em pastagens de Brachiaria. In: LIMA, M.A.; CABRAL, O.M.R. \& MIGUEZ, J.D.G., eds. Mudanças climáticas globais e a agropecuária brasileira. Jaguariúna, Embrapa Meio Ambiente, 2001. p.213-229.

BONDE, T.A.; CHRISTENSEN, B.T. \& CERRI, C.C. Dynamics of soil organic matter as reflected by natural ${ }^{13} \mathrm{C}$ abundance in particle size fractions of forest and cultivated Oxisols. Soil. Biol. Biochem., 24:275-277, 1992.

BREMNER, J.M. Nitrogen total. In: SPARKS, D.L., ed. Methods of soil analysis. Part 3. Madison, America Society of Agronomy, 1996. p.1085-1121. (SSSA Book Series, 5)

CAMBARDELLA, C.A. \& ELLIOTT, E.T. Particulate soil organic-matter changes across a grassland cultivation sequence. Soil Sci. Soc. Am. J., 56:777-783, 1992.

CHRISTENSEN, B.T. Carbon in primary and secondary organomineral complexes. In: CARTER, M.R. \& STEWART, B.A., eds. Structure and organic matter storage in agricultural soils. Boca Raton, CRC Press, 1996. p.97-165.

CHRISTENSEN, B.T. Physical fractionation of soil and organic matter in primary particle size and density separates. Adv. Soil Sci., 20:1-90, 1992.

COLLINS, H.P.; PAUL, E.A.; PAUSTIAN, K. \& ELLIOTT, E.T. Characterization of soil organic carbon relative to its stability and turnover. In: PAUL, E.A.; PAUSTIAN, K.; ELLIOTT, E.T. \& COLE, C.V., eds. Soil organic matter in temperate agroecossystems: Long-term experiments in North America. Boca Raton, CRC Press, 1997. p.51-72. 
COMISSÃO DE FERTILIDADE DO SOLO DO ESTADO DE MINAS GERAIS - CFSEMG. Recomendações para o uso de corretivos e fertilizantes em Minas Gerais, $4^{\mathrm{a}}$ aproximação. Lavras, Universidade Federal de Lavras, 1989. $176 \mathrm{p}$.

D'ANDRÉA, A.F.; SILVA, M.L.N.; CURI, N. \& GUILHERME, L.R.G. Estoques de carbono e nitrogênio e formas de nitrogênio mineral em um solo submetido a diferentes sistemas de manejo. Pesq. Agropec. Bras., 39:179-186, 2004.

DALAL, R.C. \& MAYER, R.J. Long-term trends in fertility of soils under continuous cultivation and cereal cropping in southern Queensland. I. Total organic carbon and its rate of loss from the soil profile. Aust. J. Soil Res., 24:281-292, 1986.

DAY, P.R. Particle fractionation and particle-size analysis. In: BLACK, C.A., ed. Methods of soil analysis. Madison, American Society of Agronomy, 1965. Part.1. p.545-566.

DORAN, J.W. \& PARKIN, T.B. Defining and assessing soil quality. In: DORAN, J.W.; COLEMAN, D.F.; BEZDICEK, D.F. \& STEWART, B.A., eds. Defining soil quality for a sustainable environment. 2.ed. Madison, Soil Science Society of America, 1994. p.3-22.

EMPRESA BRASILEIRA DE PESQUISA AGROPECUÁRIA EMBRAPA. Serviço nacional de levantamento e conservação do solo. Manual de métodos de análise do solo. Rio de Janeiro, 1979. 247p.

EMPRESA BRASILEIRA DE PESQUISA AGROPECUÁRIA EMBRAPA. Sistema brasileiro de classificação de solo. Brasília, Serviço de Produção de Informação, 1999. 412p.

FELLER, C. \& BEARE, M.H. Physical control of soil organic matter dynamics in the tropics. Geoderma, 79:69-116, 1997.

FERREIRA, D.F. Análises estatísticas por meio do Sisvar para Windows 4. 0. In: REUNIÃO ANUAL DA REGIÃO BRASILEIRA DA SOCIEDADE INTERNACIONAL DE BIOMETRIA, 45., São Carlos, 2000. Anais. São Carlos, Universidade Federal de São Carlos, 2000. p.255-258.

FREITAS, P.L.; BLANCANEAUX, P.; GAVINELLI, E.; LARRÉLARROUY, M.C. \& FELLER, C. Nível e natureza do estoque orgânico de Latossolos sob diferentes sistemas de uso e manejo. Pesq. Agropec. Bras., 35:157-170, 2000.

FREIXO, A.A.; MACHADO, P.L.O.A.; GUIMARÃES, C.M.; SILVA, C.A. \& FADIGAS, F.S. Estoques de carbono e nitrogênio e distribuição de frações orgânicas de Latossolo do Cerrado sob diferentes sistemas de cultivo. R. Bras. Ci. Solo, 26:425-434, 2002a.

FREIXO, A.A.; MACHADO, P.L.O.A.; SANTOS, H.P.; SILVA, C.A. \& FADIGAS, F.S. Soil organic carbon and fractions of a Rhodic Ferralsol under the influence of tillage and crop rotation systems in southern Brazil. Soil Till. Res., 64:221-230, 2002b.

GAVINELLI, E.; FELLER, C.; LARRÉ-LARROUY, M.C. \& BACYE, B. A routine method to study soil organic matter by particle-size fractionation: Examples for tropical soils. Comm. Soil Sci. Plant Anal., 26:1749-1760, 1995.
GUGGENBERGER, G.; CHRISTENSEN, B.T. \& ZECH, W. Land-use effects on the composition of organic matter in particle-size separates of soil: I. Lignin and carbohydrate signature. Eur. J. Soil Sci., 45:449-458, 1994.

JANZEN H. H.; CAMPBELL C.A.; BRANDT, S.A.; LAFOND G.P. \& TOWNLEY-SMITH L. Light-fraction organic matter in soils from long term crop rotations. Soil Sci. Soc. Am. J., 56:1799-1806, 1992.

LEITE, L.F.C.; MENDONÇA. E.S.; NEVES, J.C.L.; MACHADO, P.L.O.A. \& GALVÃO, J.C.C. Estoques totais de carbono orgânico e seus compartimentos em Argissolo sob floresta e sob milho cultivado com adubação mineral e orgânica. R. Bras. Ci. Solo, 27:821-832, 2003.

LONGO, R.M. \& ESPÍNDOLA, C.R. C-orgânico, N-total e substâncias húmicas sob influência da introdução de pastagens (Brachiaria sp.) em áreas de Cerrado e Floresta Amazônica. R. Bras. Ci. Solo, 24:723-729, 2000.

MACHADO, P.L.O.A. Fracionamento físico do solo por densidade e granulometria para a quantificação de compartimentos da matéria orgânica do solo: Um procedimento para a estimativa pormenorizada do seqüestro de carbono pelo solo. Rio de Janeiro, Embrapa Solos, 2002. 6p. (Comunicado Técnico, 9)

PARFITT, R.L.; THENG, J.S.; WHITTON, J.S. \& SHEPHERD, T.G. Effects of clay minerals and land use on organic matter pools. Geoderma, 75:1-12, 1997.

PAVAN, M.A.; CHAVES, J.C.D.; SIQUEIRA, R.; ANDROCIOLI FILHO, A.; COLOZZI FILHO, A. \& BALOTA, E.L. High coffee population density to improve fertility of an Oxisol. Pesq. Agropec. Bras., 34:459-465, 1999.

PAVAN, M.A. \& CHAVES, J.C.D. Alterações nas frações de fósforo no solo associadas com a densidade populacional de cafeeiros. R. Bras. Ci. Solo, 20:251-256, 1996.

PILLON, C.N.; MIELNICZUK, J. \& MARTIN NETO, L. Seqüestro de carbono por sistemas de manejo do solo e seus reflexos sobre o efeito estufa. In: ENCONTRO BRASILEIRO DE SUBSTÂNCIAS HÚMICAS, 4., Viçosa, MG, 2001. Anais. Viçosa, MG, 2001. 289p.

PINHEIRO, E.F.M.; PEREIRA, M.G.; ANJOS, I.H.C. \& MACHADO, P.L.O.A. Fracionamento densimétrico da matéria orgânica do solo sob diferentes sistemas de manejo e cobertura vegetal em Paty do Alferes (RJ). R. Bras. Ci. Solo, 28:731-737, 2004.

ROSCOE, R. \& MACHADO, P.L.O.A. Fracionamento físico do solo em estudos da matéria orgânica. Rio de Janeiro, Embrapa Solos, 2002. 86p.

ROSELL, R.A.; GALANTINI, J.A. \& IGLESIAS, J.O. Organic carbon changes in soil fractions of two texturally-different Haplustolls under cultivation. In: CLAPP, C.E.; HAYES, M.H.B.; SENESI, N. \& GRIFFITH, S.M., eds. Humic substances in soil and water environments. St. Paul, IHSS, 1996. p.161-162.

SILVA, C.A.; ANDERSON, S.J. \& VALE, F.R. Carbono, nitrogênio e enxofre em frações granulométricas de dois Latossolos submetidos à calagem e adubação fosfatada. R. Bras. Ci. Solo, 23:593-602, 1999. 
SOHI, S.P.; MAHIEU, N.; ARAH, J.R.M.; POWLSON, D.S.; MADARI, B. \& GAUNT, J.L. A procedure for isolating soil organic matter fractions suitable for modeling. Soil Sci. Soc. Am. J., 65:1121-1128, 2001.

THOMAZIELLO, R.A. O cultivo do cafeeiro no sistema adensado. O Agronômico, 53:8-10, 2001.
TIESSEN, H.; SALCEDO, I.H. \& SAMPAIO, E.V.S.B. Nutrient and soil organic matter dynamics under shifting cultivation in semiarid northeastern Brazil. Agric. Ecosyst. Environ., 38:139-151, 1992.

YEOMANS, J.C. \& BREMNER, J.M. A rapid and precise method for routine determination of organic carbon in soil. Comm. Soil Sci. Plant Anal., 19:1467-1476, 1988. 